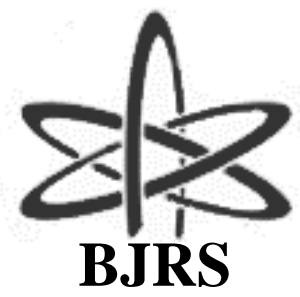

\author{
BRAZILIAN JOURNAL \\ $\mathrm{OF}$ \\ RADIATION SCIENCES \\ 09-01A (2021) 01-20
}

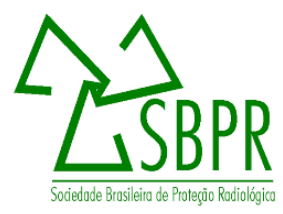

\title{
Volume fractions calculation of a biphasic system on cylindrical tube using gamma-ray and MCNP6 code
}

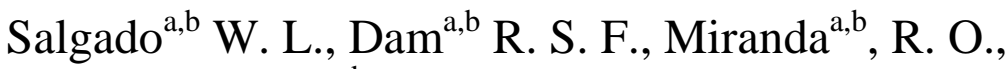 \\ Salgado $^{b}$ C. M. and Silva ${ }^{a}$ A. X. \\ ${ }^{a}$ Programa de Engenharia Nuclear - (PEN/COPPE) \\ Universidade Federal do Rio de Janeiro - (UFRJ) \\ Avenida Horácio de Macedo 2030, G- 206 \\ 21941-914 Cidade Universitária, RJ, Brazil \\ wlsalgado@con.ufrj.br; rdam@con.ufrj.br; rmiranda@nuclear.ufrj.br; ademir@con.ufrj.br \\ ${ }^{b}$ Instituto de Engenharia Nuclear - (IEN) \\ Rua Hélio de Almeida 75 \\ 21941-906 Cidade Universitária, RJ, Brazil \\ otero@ien.gov.br
}

\begin{abstract}
This paper presents a methodology to calculate volumetric fractions on the stratified flow regime, considering a cylindrical tube. A mathematical model of a measurement system was developed using the MCNP6 code. The mathematical equation was developed to calculate the volume fractions using the pulse height distributions obtained by a radiation detector. The stratified flow regime model considers air-oil, air-gasoline and oil-gasoline biphasic flow, in order to evaluate the performance of the proposed equation in fluid combinations with different densities. A comparative study with equations developed for square-section tubes from literature was performed. The study considered geometry of a source of ${ }^{137} \mathrm{Cs}$, an acrylic tubing measuring $8.0 \mathrm{~cm}$ in diameter and a $\mathrm{NaI}(\mathrm{Tl})$ scintillator detector placed at a position diametrically opposed to a radiation source to measure the transmitted beam. The dimensions and materials to perform the simulation of the detectors were based on information obtained from the gammagraphy technique and the detector was experimentally validated. The volume fractions of each of the fluids were 0 up to $100 \%$ with variations of $25 \%$.
\end{abstract}

Keywords: volume fraction, MCNP6 code, ray-gamma densitometry. 


\section{INTRODUCTION}

Due to the great demand for oil and its derivatives, extraction, refining and distribution are operations of great importance for the economy of a country. For the petroleum exploration and production industry, there is a clear need for devices that allow precise flow measurements. The most different technologies are used in the devices available on the market. However, many researchers have been investigating new methods that allow real-time and non-invasive measurement of important flow parameters, such as: flow rate, volume fraction, fluid and velocity [1 - 4]. These characteristics open a promising field for use of nuclear techniques.

Devices based on nuclear techniques are compact and efficient for flow control which is extremely useful for the development of meters that provide accurate results for all fluids present in the multiphase flow, which is very important mainly for fiscal purposes.

In this context, techniques that use gamma radiation sources have been applied to found flow characteristics rate. The great advantage of this technique, non-invasive, is the possibility of analysis the flow regime without the need to interrupt the normal operation of the installation presenting reliability in the results. In addition, the high detection sensitivity of radiation detectors allows the use of sealed radioactive sources in order to minimize the radiological risk to the health of workers. These advantages make these techniques very important in the industry and for this reason is the focus of this research [2].

Gamma densitometry has been applied in many areas, such as: chemical, mining and petroleum industry, in many applications, such as: flow measurements [5 - 7], monitoring of petroleum and petroleum by-products [8], calculations of volume fractions [4] and prediction of fluid densities [9 $10]$.

The gamma-ray densitometry technique used is based on the incidence of a gamma ray beam which after interacting with the tube-fluid system is recorded by a $\mathrm{NaI}(\mathrm{Tl})$ detector diametrically positioned to a gamma ray source $\left({ }^{137} \mathrm{Cs}\right)$. Using this technique was possible to calculate the volume fractions of different fluid present inside a tube. Using the MCNP6 computational code [11], a measurement geometry based on the transmitted beam was developed with the aim of generating many volume fractions of a stratified flow regime under a two-phase flow. The photopeak region of 
spectrum recorded in the detector is used for calculating volume fractions in a cylindrical section tube by the analytical equation. The mathematical model of a real $\mathrm{NaI}(\mathrm{Tl})$ detector was validated experimentally [12 - 18]. Therefore, this study aims to evaluate the accuracy of the analytical equation described in the literature for calculations of volume fractions in cylindrical pipelines on stratified flow regime in different fluid models (air-oil, air-gasoline and oil-gasoline) using the MCNP6 code.

\section{METHODOLOGY}

The methodology consists of developing a mathematical model using the Monte Carlo method through MCNP6 code to simulate a measurement geometry that consists of a tube and two different fluids in order to calculate the volumetric fractions of each fluid.

\subsection{Equipment and radioactive sources}

The characteristics of the spectrometric system and the radioactive sources used in this study are described:

i) Spectrometry system: A set of electronic modules used to obtain and process the signal generated by the detector was used. The characteristics of the spectrometric system used are:

- High voltage power source manufactured by Canberra 3106D;

- Pre-amplifier manufactured by the company Canberra model 2005;

- Amplifier manufactured by the company Tennelec model TC245;

- Mono Channel Analyzer manufactured by Ortec model 551;

- Multi-channel analyzer (AMC) manufactured by Instituto de Engenharia Nuclear;

- $1 \frac{114}{4} \times 3 / 4^{\prime \prime} \mathrm{NaI}(\mathrm{Tl})$ detector.

ii) Radioactive Sources: The mathematical model of the detector was validated by means of experimental measurements, using radioactive standards comprising the energy range of interest of 
this investigation (from $59.541 \mathrm{keV}$ to $661.657 \mathrm{keV}$ ). The characteristics of the gamma radioactive sources that were used in calculations are shown in Table 1.

Table 1: Data from the standard sources of radiation.

\begin{tabular}{ccccc}
\hline Source & $\begin{array}{c}\text { Energy } \\
\text { (keV) }\end{array}$ & $\begin{array}{c}\text { Half-Life } \\
\text { (days) }\end{array}$ & $\begin{array}{c}\text { Probability of } \\
\text { emission (\%) }\end{array}$ & $\begin{array}{c}\text { Activity } \\
(\mathbf{k B q})\end{array}$ \\
\hline${ }^{137} \mathrm{Cs}$ & 661.657 & 10976 & 84.99 & 22980.602 \\
${ }^{133} \mathrm{Ba}$ & 356.013 & 3849 & 62.05 & 17800.313 \\
${ }^{241} \mathrm{Am}$ & 59.541 & 158007 & 35.92 & 28154.197 \\
\hline \multicolumn{5}{c}{ * Activity corrected for the date of the experiment. }
\end{tabular}

It is important to mention that the ${ }^{133} \mathrm{Ba}$ has other energies $(276.399,302.851$ and $383.849 \mathrm{keV})$ close to the energy used in this paper $(356.013 \mathrm{keV})$, and the $\mathrm{NaI}(\mathrm{Tl})$ detector has no energy resolution to completely discriminate these peaks. Therefore, a mathematical treatment was used to calculate exclusively the desired photopeak area. In this procedure it was considered the contribution of the counts for each of these peaks, since their respective energies and energy resolution are well known.

\subsection{Absolute detector efficiency curve}

The photopeak absolute efficiency obtained experimentally with radioactive standards, listed in Table 1, was used to validate the model of the $\mathrm{NaI}(\mathrm{Tl})$ detector. The measurement time was 60 minutes and the detector source distance (DSD) of $28 \mathrm{~mm}$ was chosen so that the associated errors due to the counting statistic remained below 5\%. The simulation was done under the same conditions of experimental arrangement [19].

The emission probability of each monoenergetic photopeak associated with the corrected activity for the date of the measurements of each radioactive source was used to calculate the counting efficiency, thus determining an experimental efficiency curve of the $\mathrm{NaI}(\mathrm{Tl})$ detector. The photopeak absolute efficiency can be calculated from Equation 1.

$$
\varepsilon(E)=\frac{C}{t \cdot A \cdot P}
$$

Where: 
$C$ - number of counts recorded in the detector in the photoelectric region;

$t$ - count time (s);

$A$ - activity of the radioactive source $(\mathrm{Bq})$;

$P$ - emission probability for gamma rays in energy "E".

The uncertainty of the absolute efficiency is given by Equation 2, disregarding the uncertainties of the counting time, the emission probability and the decay correction constant, since they are very small values.

$$
\sigma \varepsilon=\sqrt{\left(\frac{\partial \varepsilon}{\partial C} \cdot \sigma C\right)^{2}+\left(\frac{\partial \varepsilon}{\partial A} \cdot \sigma A\right)^{2}}
$$

Where:

$\sigma \mathrm{C}-$ uncertainty associated with counts;

$\sigma \mathrm{A}-$ uncertainty associated with activity.

\subsection{Energy resolution curve}

In order to consider the energy resolution of the $\mathrm{NaI}(\mathrm{Tl})$ detector in the mathematical simulation, using the MCNP6 code, making it more realistic, it is necessary to use a special treatment for the Pulse height distribution (PHD), in which the energy peaks behave as a Gaussian function, broadening it according to Equation 3.

$$
f(E)=C \cdot \exp -\left(\frac{E-E_{0}}{F W H M / 2 \sqrt{\ln 2}}\right)^{2}
$$

Where:

E - "broadening" energy $(\mathrm{MeV})$;

$\mathrm{E}_{0}$ - "non- broadening” energy $(\mathrm{MeV})$;

$\mathrm{C}$ - normalization constant $(\mathrm{MeV})$;

FWHM $/ 2 \sqrt{\ln 2}-$ Gauss width $(\mathrm{MeV})$;

FWHM - Full Width at Half Maximum. 
This treatment is performed using parameters that are supplied by the user to the input file (INP) with the Gaussian Energy Broadening (GEB) command of the FTn card, available in the MCNP6 code. These parameters were experimentally obtained from the least squares approximation of the nonlinear function of Equation 4.

$$
F W H M=a+b \sqrt{E+c E^{2}}
$$

Where:

$E-$ Energy of incident gamma rays $(\mathrm{MeV})$;

$a, b, c$-adjusted constants.

\section{$2.4 \quad \mathrm{NaI}(\mathrm{Tl})$ detector modeling}

The detector must be modeled as accurately as possible because variations in crystal size influence the determination of efficiency [20 - 23]. When the technical manuals do not declare the information (shape of the crystal and the dimensions of the active volume) about the characteristics of a detector or even when the model or manufacturer of the detector is not known, such information can be obtained by performing a gammagraphy [24]. The density of the $\mathrm{NaI}(\mathrm{Tl})$ crystal used was $3.667 \mathrm{~g} . \mathrm{cm}^{-3}$, the density of the reflective material $(\mathrm{MgO})$ used was $3.58 \mathrm{~g} . \mathrm{cm}^{-3}$ and the aluminum density was 2.6989 g.cm ${ }^{-3}[14-16]$.

Despite this, the actual dimensions of the crystal may be different, in order to determine these values accurately, two point sources, ${ }^{241} \mathrm{Am}$ and ${ }^{137} \mathrm{Cs}$, one low and one high energy, respectively, were used. These sources were measured with the $\mathrm{NaI}(\mathrm{Tl})$ detector at a DSD of $28 \mathrm{~mm}$, positioned in the direction of the longitudinal axis in relation to the crystal. Two measurements were made with the sources on the longitudinal axis of the detector in order to determine the detector response to a known radiation field. This geometry was reproduced by simulation and the results were compared with the experimental values.

The procedure for determining the real volume of the detector consists of an iterative process between the counts obtained in the simulation and the variation of the crystal thickness made in the INP. The calculations started with the value obtained by the gammagraphy which is $31.75 \mathrm{~mm}$ in 
diameter and $19.05 \mathrm{~mm}$ in thickness. With these values it was verified that the total recorded count was larger than that obtained experimentally. The thickness of the crystal was gradually reduced until the value of the total count obtained was in agreement with the experimental value, thus defining the actual crystal volume [22, 23]. It is worth noting that this procedure wasn't performed varying the crystal diameter in the mathematical model, therefore, crystal lateral efficiency was not considered.

The simulation response was obtained using the output command "tally card F8", available in the MCNP6 code, which presents a PHD due to the photons in the sensitive region of the crystal. The mathematical modeling considered homogeneous detectors of sodium iodide activated with thallium: $\mathrm{NaI}(\mathrm{Tl})$ [14 - 18], according to our previous papers [25-26]. Some important considerations should be mentioned: The photomultiplier, positioned behind the crystal, was simulated as a $30 \mathrm{~mm}$ thick aluminum disc [17]. A radioactive source of the isotropic emission volumetric type is simulated in the code. The electrons generated by gamma radiation in the $\mathrm{NaI}(\mathrm{Tl})$ crystal are completely absorbed by the crystal thickness, so they were not considered in the simulation.

\subsection{Volume fractions}

The method is based on the attenuation of a gamma-ray monoenergetic beam transmitted by a tube containing biphasic flow. Considering a simplified model of the stratified flow regime with liquid phases in a square cross-section tube, knowing the dimensions and characteristics of the tube, the intensity of the beam transmitted is given by the equation of Beer-Lambert's modified, according to Equation 5. Disregarding a tube thickness since the term is common in calculating the volume fraction, and therefore, attenuation in the tube wall is also disregarded.

$$
\mathrm{I}(\mathrm{E})=\mathrm{I}_{0}(\mathrm{E}) \cdot \exp \left(-\sum_{1}^{\mathrm{n}} \mathrm{x}_{\mathrm{i}} \mu_{\mathrm{i}}(\mathrm{E})\right)
$$

Where:

$I-$ transmitted intensity of gamma rays (photons. $\mathrm{cm}^{-2} \cdot \mathrm{s}^{-1}$ );

$I_{0}$ - initial incident intensity of gamma rays from the source (photons. $\mathrm{cm}^{-2} \cdot \mathrm{s}^{-1}$ ); 
$x_{i}-$ thickness for fluid i $(\mathrm{cm})$;

$E$ - incident radiation energy;

$\mu_{i}$ - linear attenuation coefficient for fluid i.

A source collimated with enough energy to penetrate and be transmitted throughout the tubefluid system is positioned on one side and diametrically opposite the source, a $\mathrm{NaI}(\mathrm{Tl})$ scintillation detector is installed to record the incident beam counts. The signal recorded in the detector is proportional to the transmission of the gamma rays due to the tube-fluid system. High-density fluids cause a decrease in the counting rate at the detector, while the lower density fluids result in a higher counting rate. Considering a unidirectional measurement geometry and perpendicular to the fluid layers in a biphasic system, as shown in Figure 1.

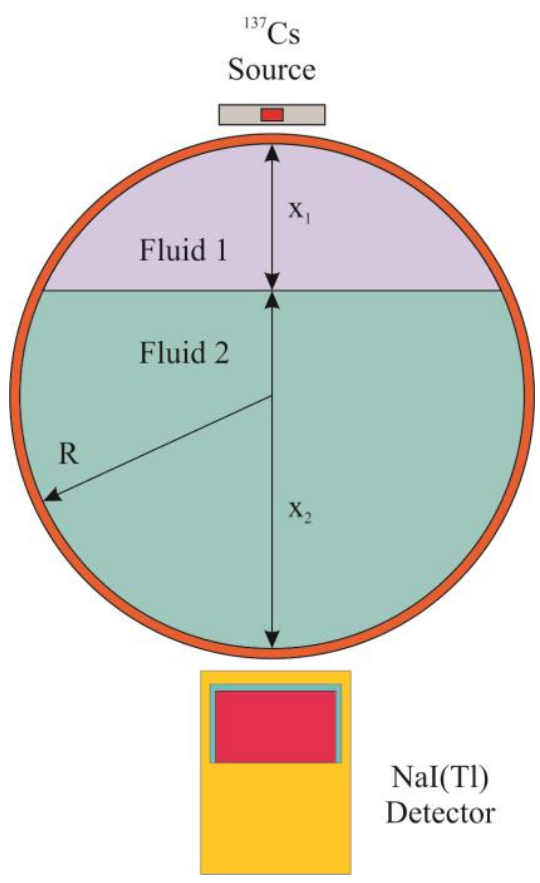

Figure 1: Geometry used for volume fractions calculation.

The calculation of the fluid volume fraction (FVF) in heterogeneous biphasic systems under the stratified flow regime using the gamma attenuation technique can be obtained using Equations 6 and $7[1]$. 


$$
\begin{aligned}
\alpha_{1} & =\frac{\ln \left(\mathrm{I} / \mathrm{I}_{2}\right)}{\ln \left(\mathrm{I} / \mathrm{I}_{1}\right)} \\
\alpha_{2} & =1-\alpha_{1}
\end{aligned}
$$

Where:

$\alpha_{1,2}-$ volume fraction of fluid 1 or $2(\%)$;

I - gamma ray intensity recorded with tube containing fluids 1 and 2 (photons. $\mathrm{cm}^{-2} \cdot \mathrm{s}^{-1}$ );

$\mathrm{I}_{1,2}$ - intensity containing only fluid 1 or 2 (photons. $\mathrm{cm}^{-2} \cdot \mathrm{s}^{-1}$ ).

For a cylindrical straight section tube, it is quite complex to calculate, therefore, the procedure adopted was to calculate the thicknesses of each fluid that correspond to the path traveled by the radiation considering a pencil beam, which can be obtained by Equations 8 and 9 [1].

$$
\begin{aligned}
& \mathrm{x}_{1}=\frac{\ln \left(\mathrm{I} / \mathrm{I}_{2}\right)}{\mu_{2}-\mu_{1}} \\
& \mathrm{x}_{2}=\frac{\ln \left(\mathrm{I} / \mathrm{I}_{1}\right)}{\mu_{1}-\mu_{2}}
\end{aligned}
$$

Where:

$\mu_{1,2}-$ coefficient of linear attenuation of fluid 1 and 2 .

Knowing the thicknesses of the fluids inside the tube, it is necessary to calculate the integral of the area occupied by the fluids by Equation 10.

$$
S(x)=2 \cdot \int_{0}^{h} \sqrt{R^{2}-(y-R)^{2}} d y
$$

Where:

$\mathrm{R}$ - radius of the tube $(\mathrm{cm})$;

$\mathrm{y}$ - mathematical parameter to calculate the integral.

By means of mathematical manipulations and using the trigonometric method, the calculation of the volume fraction is given by Equation 11 [27]. 


$$
\alpha(x)=\frac{\pi R^{2}}{2}+R^{2} \cdot \sin ^{-1}\left(\frac{x-R}{R}\right)+(x-R) \cdot \sqrt{R^{2}-(x-R)^{2}}
$$

\subsection{Proposed geometry of the detection system}

The study considered a detection geometry composed of a ${ }^{137} \mathrm{Cs}$ source $(661.657 \mathrm{keV})$, an acrylic tube with a $3.5 \mathrm{~cm}$ internal diameter and a wall thickness of $0.5 \mathrm{~cm}$ and a $\mathrm{NaI}(\mathrm{Tl})$ scintillation detector, positioned diametrically opposite the source, to measure the transmitted beam, as shown in Figure 1. The interior of the tube was filled with different amounts of the fluids to investigate the attenuation of the gamma rays in the calculation of the volume fractions. The stratified flow regime model considers fluid 1 and 2 (air-oil or air-gasoline or oil-gasoline), in order to evaluate the performance of the proposed equation in fluid combinations with different densities (air - 1.205E-3, gasoline - 0.721 and oil -0.955 g.cm ${ }^{-3}$ ). The calculation used the "Tally F8" command to estimate the simulated pulse height distribution (PHD), ranging from 40 to $800 \mathrm{keV}$. This energy range was chosen considering the $661.657 \mathrm{keV}$ emission photopeak of the ${ }^{137} \mathrm{Cs}$. The fluids used are air, gasoline $\left(\mathrm{C}_{8} \mathrm{H}_{18}\right)$ and oil $\left(\mathrm{C}_{10} \mathrm{H}_{18} \mathrm{O}\right)$. The volumetric fractions were varied from 0 , $25,50,75$ and $100 \%$. It is important to mention that only the photopeak area was used in the analytical equations to calculate the volume fractions of the fluids.

\section{RESULTS AND DISCUSSIONS}

\subsection{Detector validation}

In order to evaluate if the proposed mathematical model is in agreement with the reality, the experimental photopeak absolute efficiency was compared with the values obtained on mathematical model of the detector $\mathrm{NaI}(\mathrm{Tl})$ considering the same geometry used in the experimental procedures. Uncertainty was estimated considering the counts and activity and remained below 5\%. The experimental and simulated photopeak absolute efficiencies are shown in Table 2.

Table 2: Experimental and simulated efficiency values.

\begin{tabular}{|c|c|c|c|c|}
\hline \multirow{2}{*}{ Radionuclide } & \multirow{2}{*}{$\begin{array}{c}\text { Energy } \\
\text { (keV) }\end{array}$} & \multicolumn{2}{|c|}{ Efficiency $(\%)$} & \multirow{2}{*}{$\begin{array}{c}\text { Relative Error } \\
(\%)\end{array}$} \\
\hline & & Experimental & Simulation & \\
\hline
\end{tabular}




\begin{tabular}{ccccc}
\hline Am-241 & 59.541 & $1.71 \pm 0.05$ & 1.71 & 0.18 \\
Ba-133 & 356.013 & $0.66 \pm 0.12$ & 0.65 & 2.87 \\
Cs-137 & 661.657 & $0.17 \pm 0.01$ & 0.17 & 0.07 \\
\hline
\end{tabular}

The experimental data and the values obtained by the modeling showed good agreement and presented a maximum relative error of $2.87 \%$ indicating that the detector model was well developed.

The energy resolution of the detector was determined by mean of the Full Width at Half Maximum (FWHM) measurements in photopeak energy from each source. From the experimentally FWHM measured, the parameters $a, b$ and $c$ used to adjust the GEB function were calculated by Equation 4 described in section 2.3, the coefficients values are presented in Table 3 and the function represented in Figure 2.

With these results it became possible to perform the fit of the GEB function, through the mentioned methodology, making the mathematical model more realistic.

Table 3: Coefficient values obtained by fit Equation 4 .

\begin{tabular}{ccc}
\hline Coefficients & Values & Uncertainty \\
\hline $\mathrm{a}$ & 0.009 & 0.002 \\
$\mathrm{~b}$ & -0.24 & 0.01 \\
$\mathrm{c}$ & -0.35 & 0.02 \\
\hline
\end{tabular}




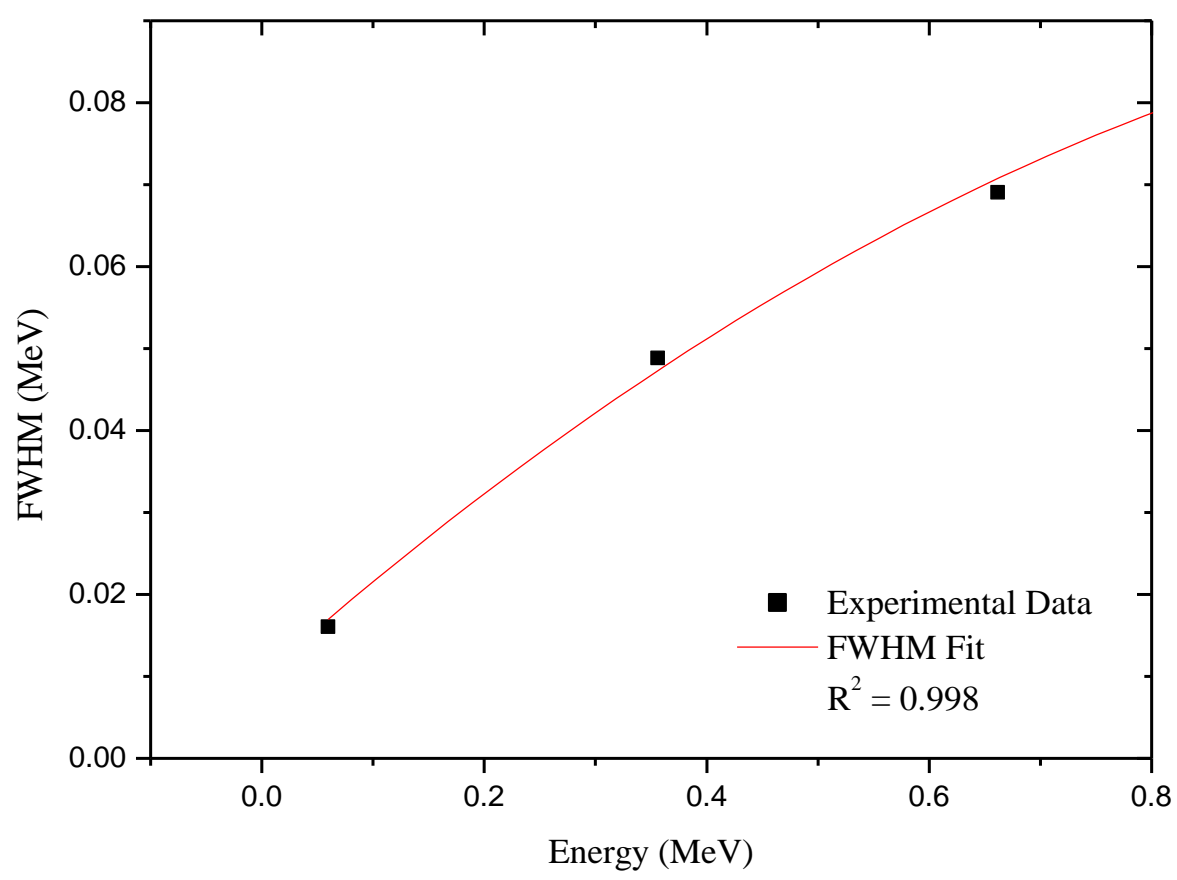

Figure 2: Full width at half maximum response curve (FWHM).

After the experimental validation of efficiency and the considering of the energy resolution of the real detection system, a PHD for $661.657 \mathrm{keV}$ is shown in Figure 3. 


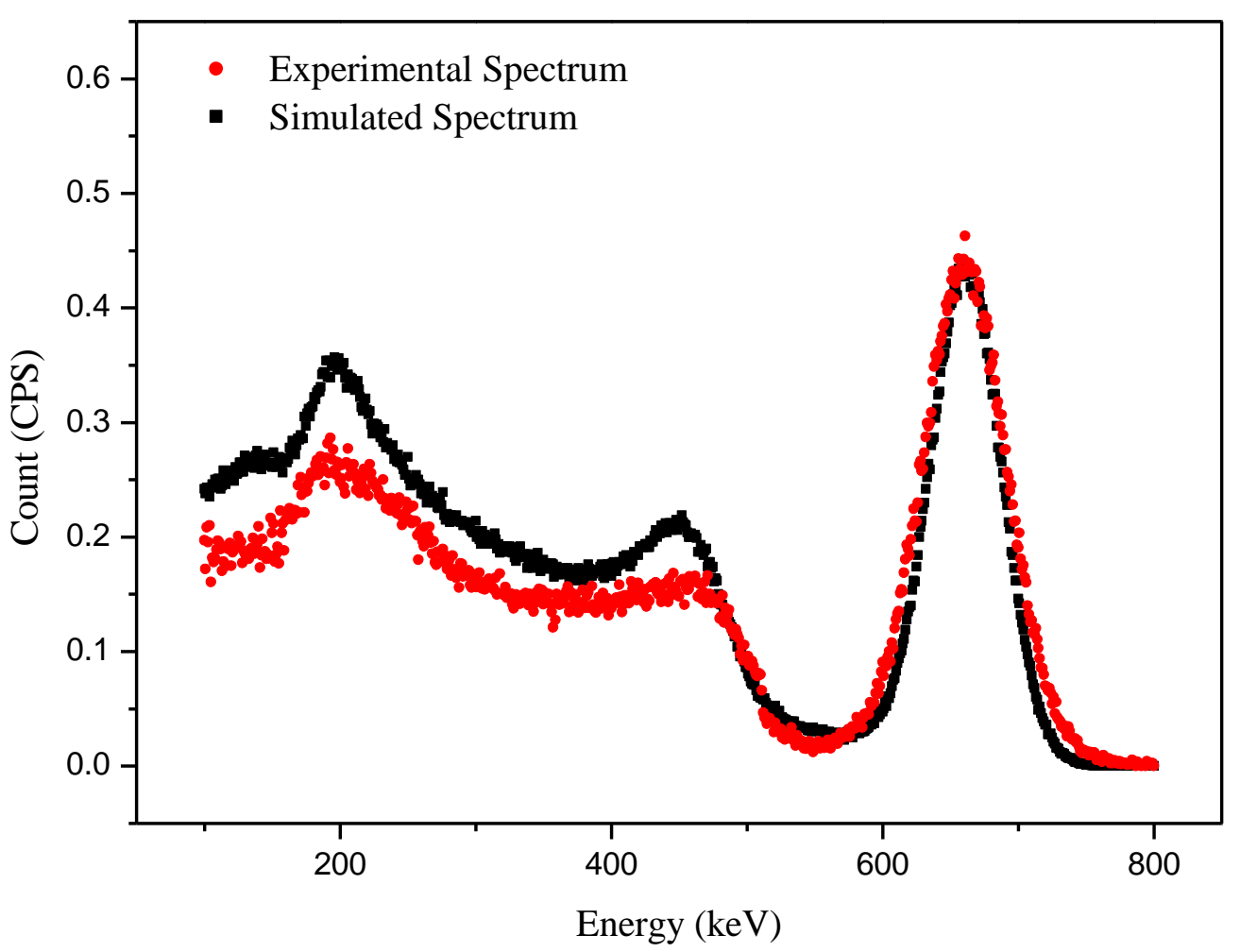

Figure 3: Comparison of the shape of the experimental and simulated spectra in the code.

An acceptable agreement can be noted in the photopeak region, but in the low energy range (Compton region) the PHD presents some discrepancy, which is usually reported in the literature as not-so-good precision in the simulation of low energy electrons and by scattering of photons in the shield and detector support that not considered in the simulations [13].

\subsection{Volume fraction results}

The spectra recorded by the detector for gasoline and oil flow are shown in Figure 4. Important to mention that air-oil and air-gasoline flow are very similar. The percentages refer to the oil fluid. Therefore, $0 \%$ means $0 \%$ oil, or $100 \%$ gasoline. Different fluid volume fractions equal to $0,25,50$, 75 and $100 \%$ in relation to the other fluid were simulated on the biphasic system. 


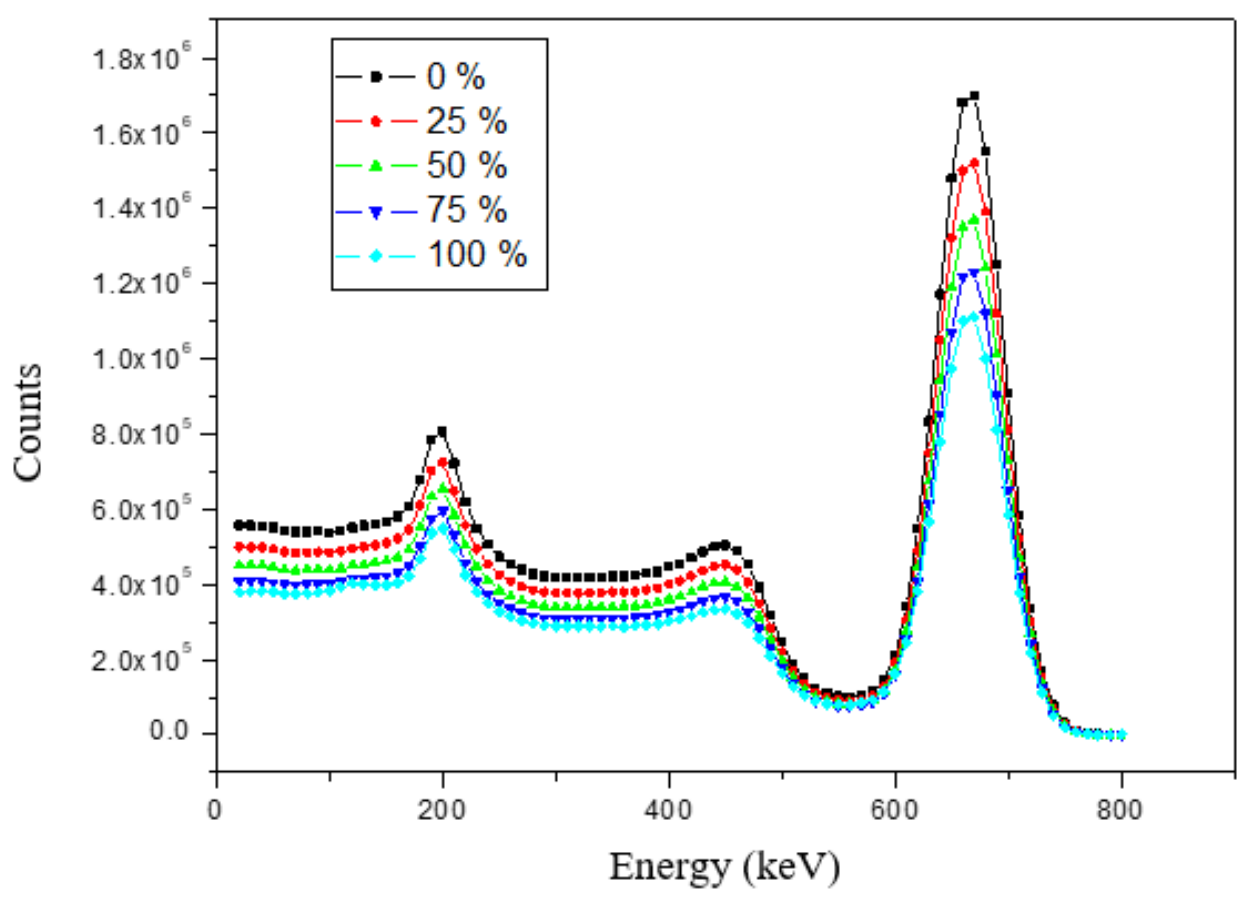

Figure 4: Spectra obtained with the simulation of oil and gasoline.

The calculation of the volume fraction using the measurements by transmission was performed by means of the integral of counts referring to the photopeak area obtained by the detector, since it is the region of total absorption of energy being well characterized, as can be seen in Figure 4 .

The results for the volumetric fractions were obtained by means of the Equations 6 and 11 to verify if both equations can be used for cylindrical tubes; these results can be visualized in Tables 4 , 5 and 6.

Table 4: Comparison of the results for the oil-gasoline system.

\begin{tabular}{ccccc}
\hline \multicolumn{4}{c}{ Oil - Gasoline } \\
\hline \multirow{2}{*}{$\begin{array}{c}\text { Theoretical } \\
\text { Volume (\%) }\end{array}$} & \multicolumn{2}{c}{ Square Tube } & \multicolumn{2}{c}{ Cylindrical Tube } \\
\cline { 2 - 5 } & $\begin{array}{c}\text { Simulated } \\
\text { Volume (\%) }\end{array}$ & $\begin{array}{c}\text { Relative } \\
\text { Error (\%) }\end{array}$ & $\begin{array}{c}\text { Simulated } \\
\text { Volume (\%) }\end{array}$ & $\begin{array}{c}\text { Relative } \\
\text { Error (\%) }\end{array}$ \\
\hline 25.00 & 29.70 & 18.80 & 24.87 & 0.52 \\
50.00 & 49.92 & 0.16 & 49.87 & 0.26 \\
75.00 & 69.85 & 6.86 & 74.56 & 0.59 \\
\hline
\end{tabular}


Table 5: Comparison of the results for the oil-air system.

\begin{tabular}{|c|c|c|c|c|}
\hline \multicolumn{5}{|c|}{ Oil - Air } \\
\hline \multirow{2}{*}{$\begin{array}{l}\text { Theoretical } \\
\text { Volume }(\%)\end{array}$} & \multicolumn{2}{|c|}{ Square Tube } & \multicolumn{2}{|c|}{ Cylindrical Tube } \\
\hline & $\begin{array}{c}\text { Simulated } \\
\text { Volume }(\%)\end{array}$ & $\begin{array}{c}\text { Relative } \\
\text { Error }(\%) \\
\end{array}$ & $\begin{array}{c}\text { Simulated } \\
\text { Volume }(\%)\end{array}$ & $\begin{array}{c}\text { Relative } \\
\text { Error }(\%) \\
\end{array}$ \\
\hline 25.00 & 29.85 & 19.39 & 24.93 & 0.28 \\
\hline 50.00 & 49.97 & 0.05 & 49.74 & 0.52 \\
\hline 75.00 & 70.22 & 6.37 & 74.74 & 0.35 \\
\hline
\end{tabular}

Table 6: Comparison of the results for the gasoline-air system.

\begin{tabular}{ccccc}
\hline \multicolumn{4}{c}{ Gasoline - Air } \\
\hline \multirow{2}{*}{$\begin{array}{c}\text { Theoretical } \\
\text { Volume (\%) }\end{array}$} & \multicolumn{2}{c}{ Square Tube } & \multicolumn{2}{c}{ Cylindrical Tube } \\
\cline { 2 - 5 } & $\begin{array}{c}\text { Simulated } \\
\text { Volume (\%) }\end{array}$ & $\begin{array}{c}\text { Relative } \\
\text { Error (\%) }\end{array}$ & $\begin{array}{c}\text { Simulated } \\
\text { Volume (\%) }\end{array}$ & $\begin{array}{c}\text { Relative } \\
\text { Error (\%) }\end{array}$ \\
\hline 25.00 & 29.80 & 19.20 & 24.84 & 0.64 \\
50.00 & 49.92 & 0.16 & 49.62 & 0.76 \\
75.00 & 70.08 & 6.56 & 74.50 & 0.67 \\
\hline
\end{tabular}

The relative errors for each of the procedures performed are shown in the Tables 4, 5 and 6 , the maximum errors are around 20\% for the approximation performed through Equations 6 and 7, however for measurements with the tube filled with half of each fluid these are equations has a maximum relative error of $0.16 \%$. While, the maximum error for the developed equation is $0.76 \%$ for all the fractions of volume.

\section{CONCLUSIONS}

The modeling of a detector (crystal + housing + photomultiplier tube) by means of the MCNP6 code correctly experimental validated with measurements is a very important step in the practical implementation, since it tends to approach the real case. Moreover, it avoids the need to build 
practical models representative of the geometry under study (phantoms) in the initial phase of a project. The measurement geometry developed in the MCNP6 code the allowed to give reliability to the methodology of calculation of volumetric fractions in biphasic systems in the stratified flow regime with different fluids. The results obtained by Equations 6 and 7 presented a good approximation for calculation when the volume fractions values are equal to $50 \%(50 \%$ oil $+50 \%$ de gasoline) of each fluid presenting a maximum relative error of $0.16 \%$, obviously this result extends to the tube completely filled with oil or gasoline. However, for different volume fractions the maximum relative error was $19.39 \%$. This result shows that these equations are not suitable for calculating volume fractions in cylindrical tubes. While the results for the developed analytical equations for cylindrical tubes, (Equation 11) presented a maximum relative error of $0.76 \%$ in all cases $(25 \%, 50 \%$ and $75 \%)$, showing that the real results obtained match with the calculated volume fractions for all fluid combinations, even for the worst case oil-gasoline flow since the density is very close to each other when compared to the other combinations. Therefore, the authors recommend the use of Equation 11 in cylindrical tube in applications whose precision is fundamental.

\section{ACKNOWLEDGMENTS}

This study was financed in part by the Coordenação de Aperfeiçoamento de Pessoal de Nível Superior - Brasil (CAPES) - Finance Code 001. The authors gratefully acknowledge the financials support from Conselho Nacional de Desenvolvimento Científico e Tecnológico (CNPq) and Fundação Carlos Chagas Filho de Amparo à Pesquisa do Estado do Rio de Janeiro (FAPERJ). Thanks also to Instituto de Engenharia Nuclear (IEN).

\section{REFERENCES}


[1] ABOUELWAFA, M. S. A.; KENDALL E. J. M. The measurement of component ratios in multiphase systems using gamma-ray attenuation. Journal of Physics E: Scientific Instruments, v. 13, p. 341-345, 1980.

[2] SALGADO, C.M.; PEREIRA, C.M.NA.; SCHIRRU, R.; BRANDÃO, L.E.B. Flow regime identification and volume fraction prediction in multiphase flows by means of gamma-ray attenuation and artificial neural networks. Progress in Nuclear Energy, v. 52, p. 555-562, 2010.

[3] NAZEMI, E.; ROSHANI, G.H.; FEGHHI, S.A.H; GHOLIPOUR, P.R.; SETAYESHI, S. Precise void fraction measurement in two-phase flows independent of the flow regime using gamma-ray attenuation. Nuclear Engineering and Technology, v. 48, p. 64-71, 2016.

[4] HANUS, R.; ZYCH, M.; KUSY, M.; JASZCZUR, M.; PETRYKA, L. Identification of liquidgas flow regime in a pipeline using gamma-ray absorption technique and computational intelligence methods. Flow Measurement and Instrumentation, v. 60, p. 17-23, 2018.

[5] MI, Y.; ISHII, M.; TSOUKALAS, L.H. Vertical two-phase flow identification using advanced instrumentation and neural networks, Nuclear Engineering and Design, v. 184, p. 409-420, 1998.

[6] SALGADO, C.M.; BRANDÃO, L.E.B.; NASCIMENTO, C.M.N.A.; SCHIRRU, R.; RAMOS, R.; SILVA, A.X. Prediction of volume fractions in three-phase flows using nuclear technique and artificial neural network, Applied Radiation and Isotopes, v. 67, p. 1812-1818, 2009.

[7] SALGADO, C.M.; PEREIRA, C.M.N.A.; SCHIRRU, R.; BRANDÃO, EL.E.B. Flow regime identification and volume fraction prediction in multiphase flows by means of gamma-ray attenuation and artificial neural networks. Progress in Nuclear Energy, v. 52(6), p. 555-562, 2010.

[8] KHORSANDI, M.; FEGHHI, E.S.A.H. Design and construction of a prototype gamma-ray densitometer for petroleum products monitoring applications. Measurement, v. 44, p. 1512-1515, 2011. 
[9] ABDULRAHMAN, A.A.; SHOKIR, E.M. Artificial neural networks modeling for hydrocarbon gas viscosity and density estimation. Journal of King Saud University - Engineering Sciences, v 23, p. 123-129, 2011.

[10] SALGADO, C.M.; BRANDAO, L.E.B.; CONTI, C.C.; SALGADO, W.L. Density prediction for petroleum and derivatives by gamma-ray attenuation and artificial neural networks. Applied Radiation and Isotopes, v. 116, p. 143-149, 2016.

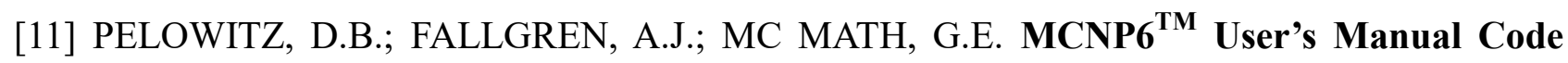
Version 6.1.1 beta. Los Alamos National Laboratory Report: LA-CP-14-00745, Los Alamos, 2014.

[12] SALGADO, C.M.; BRANDÃO, L.E.; SCHIRRU, R.; PEREIRA, C.M.N.A.; RAMOS, R.; SILVA, A.X. Modelagem de detector NaI(Tl) usando MCNP-X, In: XI Encontro de Modelagem Computacional, 2008, n. 0189, Volta Redonda, RJ.

[13] SALGADO, C.M.; BRANDÃO, L.E.B.; PEREIRA, C.M.N.A.; RAMOS, R.; SCHIRRU, R.; SILVA, A.X. Validation of a NaI(Tl) detector's model developed with MCNP-X code. Progress in Nuclear Energy, v. 59, p.19-25, 2012.

[14] BERGER, M.J.; SELTZER, S.M. Response functions for sodium iodide scintillation detectors. Nuclear Instruments and Methods, v. 104, p. 317-332, 1972.

[15] SAITO, K.; MORIUCHI, S. Monte Carlo Calculation of accurate response functions for a $\mathrm{NaI}(\mathrm{Tl})$ detector for gamma rays. Nuclear Instruments and Methods, v. 185, p. 299-308, 1981.

[16] ORION, I.; WILOPOLSKI, L. Limitations in the PHOTON Monte Carlo gamma transport code. Nuclear Instruments and Methods in Physics Research, v. 480, p. 729-733, 2002.

[17] SHI, HU-XIA, CHEN, BO-XIAN; LI TI-ZHU; YUN, D.I. Precise Monte Carlo simulation of gamma-ray response functions for an $\mathrm{NaI}(\mathrm{Tl})$ detector. Applied Radiation and Isotopes, v. 57, p. 517-524, 2002. 
[18] SOOD, A.; GARDNER, R.P. A new Monte Carlo assisted approach to detector response functions. Nuclear Instruments Methods Physics Research, v. 213, p. 100-104, 2004.

[19] EWA, I.O.B.; BODIZS, D.; CZIFRUS, S.Z.; MOLNAR, Z.S. Monte Carlo determination of full energy peak efficiency for a HPGe detector. Nuclear Instruments and methods in Physics Research, v. 479, p. 618-630, 2001.

[20] NAKAMURA, T. Monte Carlo Calculation of Peak Efficiencies of Ge(Li) and Pure Ge Detectors to Volumial Sources and Comparison with Environmental Radioactivity Measurement. Nuclear Instruments and Methods, v. 205, p. 211-218, 1983.

[21] SIMA, O. Monte Carlo Simulation versus Semiempirical Calculation of Autoabsorption Factors for Semiconductor Detector Calibration in Complex Geometries. Progress in Nuclear Energy, v. 24, p. 327-336, 1990.

[22] CONTI, C.C. Medida de KERMA no ar e determinação de coeficientes de conversão para dose devido à radiação gama ambiental, Tese de doutorado. COPPE/UFRJ, Rio de Janeiro, Brasil.

[23] CONTI, C.C.; SACHET, I.A.; BERTELLI, L; LOPES, R.T. Ge detectors calibration procedure at IRD/CNEN for in situ measurements. In: II International Symposium on Technologically Enhanced Natural Radiation, Rio de Janeiro, 1999.

[24] SAlGADO, C.M.; BRANDÃO, L.E.; SCHIRRU, R.; PEREIRA, C.M.; CONTI, C.C. Validation of a $\mathrm{NaI}(\mathrm{Tl})$ detector's model developed with MCNP-X code. Progress in Nuclear Energy, v. 59, p. 19-25, 2012.

[25] SALGADO, C.M.; BRANDÃO, L.E.B.; PEREIRA, C.M.N.A.; RAMOS, R.; SCHIRRU, R.; SILVA, A.X. Validation of a NaI(Tl) detector's model developed with MCNP-X code. Progress in Nuclear Energy, v. 59, p.19-25, 2012.

[26] SALGADO, W. L.; BRANDÃO, L. E. B. Study of volume fractions on biphasic stratified regime using gamma ray. Brazilian Journal of Radiation Sciences, v. 7, p. 1-14, 2017. 
[27] SAlGADO, W.L.; DAM, R.S.F.; BARBOSA, C.M.; SILVA, A.X.; SALGADO, C.M. Monitoring system of oil by-products interface in pipelines using the gamma radiation attenuation. Applied Radiation and Isotopes, v. 160, 2020. 